\title{
Rethinking assumptions about delivery of healthcare: implications for universal health coverage
}

\section{Simply providing more resources for universal coverage is not enough to improve health, argue} Jishnu Das and colleagues. We also need to ensure good quality of care

W

e are at an inflection point in global health. People are living longer, healthier lives than ever before, and we are rightly celebrating disease focused programmes that have greatly reduced or eradicated diseases such as smallpox and river blindness. Better diagnosis and treatment of HIV/AIDS, malaria, and other diseases have saved countless lives. ${ }^{12}$ Yet, as populations age and the burden of morbidity grows more complex, the limitations of programmes focused on single diseases have become increasingly evident.

Policy makers have shifted towards a broader "systems" view of universal health coverage (UHC) - one that seeks to provide all people with access to essential health services without financial hardship-as the defining approach to improve the health of the world's poorest people. As one of the key focuses of the sustainable development goals, UHC has become a rallying principle for all countries. Indeed, the new director general of the World Health Organization has made UHC his top priority for the agency.

UHC can achieve its primary objective of creating better health, but to do so,

\section{KEY MESSAGES}

- Availability of health advisers is not the main problem in most countries

- Simply providing access to trained medical staff and facilities does not guarantee universal access to quality care

- A weak link between medical qualifications and medical knowledge implies that providers without any formal medical training can provide higher quality care than fully trained doctors

- In many countries large gaps exist between what doctors know and what they actually do

- New approaches are needed to tackle systems that produce medical profes sionals who are poorly trained, undermotivated, and underused patients must have access to services that are high quality. This idea of "effective UHC" is not new. It has long been recognised that translating healthcare into health outcomes requires that services meet some basic standard of quality. ${ }^{3}$ However, without systematic data on quality, the working assumption has been that adequately trained doctors and nurses with access to infrastructure (such as well equipped facilities and medicines) will be sufficient to guarantee adequate quality. Emerging data suggest that this understanding may be incorrect. For example, even when resources are in place in countries as far afield as Bangladesh and Uganda, health systems are unable to ensure that doctors show up to work, with absence rates ranging from $40 \%$ to $60 \% .{ }^{45}$ And when they do, the services they provide are far below any acceptable standard.

We focus on one aspect of qualityeffectiveness, or the degree to which patients receive timely and accurate diagnoses and evidence based treatments for their conditions. ${ }^{6}$ Other domains of quality, such as patient safety and patient centredness (table 1$),{ }^{8}$ are equally important. However, the effective provision of necessary services is foundational to the performance of health systems; a system that cannot accurately diagnose or manage patients will not deliver the improved health outcomes implicit in the UHC agenda.

\section{Assessing the evidence and identifying the problems}

Our synthesis relies on recent studies of the quality of clinical practice and its determinants in low and middle income countries (LMICs). In the absence of administrative data sources or information from patient charts (which are rare or of doubtful quality in many of these countries), these studies have used surveys of healthcare providers (medical vignettes and standardised patients) to measure two related but separate things: what providers know about managing common medical conditions and how they actually practise in clinical settings (see appendix on bmj.com). Three key issues emerge from this evidence and are discussed below.

\section{Without quality, access may be irrelevant} Health policy efforts often invest substantially in programmes that have the primary objective of increasing the use of healthcare services, such as the number of treatment episodes or health visits per patient. But emerging data suggest that this focus on getting people in the door may not lead to improved health.

We often begin with the assumption that a key feature of many health systems in LMICs is the lack of access to healthcare services. We measure access by counting the number and proximity of formal healthcare providers who work in official clinics. In reality, in many countries, people may have access to multiple healthcare

\begin{tabular}{|c|c|c|}
\hline Domain & Subcategorisation & Example measures \\
\hline \multirow[t]{3}{*}{ Safety } & \multirow{2}{*}{$\begin{array}{l}\text { Adverse events-eg, due to medical devices or } \\
\text { medicines, including substandard and falsified } \\
\text { medicines }\end{array}$} & Rate of prescriptions above the maximum daily dose \\
\hline & & $\begin{array}{l}\text { Rate of infection or foreign objects left during surgical } \\
\text { procedures }\end{array}$ \\
\hline & Healthcare acquired conditions & $\begin{array}{l}\text { Cases of hospital acquired pneumonia among } \\
\text { inpatients }\end{array}$ \\
\hline \multirow[t]{3}{*}{ Effectiveness } & Timely and accurate diagnosis & Rate of correct diagnosis of cervical cancer \\
\hline & \multirow[t]{2}{*}{$\begin{array}{l}\text { Evidence based treatment, including } \\
\text { appropriate follow-up and management }\end{array}$} & $\begin{array}{l}\text { Rate of appropriate treatment for patients presenting } \\
\text { with childhood diarrhoea }\end{array}$ \\
\hline & & $\begin{array}{l}\text { Rate of glycaemic control among patients diagnosed } \\
\text { with diabetes }\end{array}$ \\
\hline \multirow[t]{2}{*}{$\begin{array}{l}\text { Patient } \\
\text { centredness }\end{array}$} & Patient experience & $\begin{array}{l}\text { Rate of patients who would recommend their provide } \\
\text { to a family or friend }\end{array}$ \\
\hline & Patient reported outcomes & $\begin{array}{l}\text { Patients reporting adequate or high functional status } \\
\text { after surgery }\end{array}$ \\
\hline
\end{tabular}




\begin{tabular}{|c|c|c|c|c|c|c|c|}
\hline \multirow[b]{2}{*}{ Location of study } & \multirow[b]{2}{*}{ Conditions studied } & \multirow[b]{2}{*}{$\begin{array}{l}\text { No of standardised } \\
\text { patients }\end{array}$} & \multirow{2}{*}{$\begin{array}{l}\text { No of healthcare } \\
\text { visits / practitioners } \\
\text { included }\end{array}$} & \multirow[b]{2}{*}{$\begin{array}{l}\text { \% With correct } \\
\text { diagnosis }\end{array}$} & \multicolumn{2}{|c|}{$\%$ Correctly managed or referred } & \multirow[b]{2}{*}{$\begin{array}{l}\% \text { given unnecessary } \\
\text { antibiotics }\end{array}$} \\
\hline & & & & & $\begin{array}{l}\text { No unnecessary } \\
\text { drugs given }\end{array}$ & $\begin{array}{l}\text { Some unnecessary } \\
\text { drugs given }\end{array}$ & \\
\hline \multicolumn{8}{|l|}{ India: } \\
\hline \multirow[t]{2}{*}{ Delhi (urban) } & Angina, asthma, and diarrhoea & 17 & 250 & 23 & 46 & NA & NA \\
\hline & Tuberculosis & 17 & 250 & NA & 8 & 21 & 54 \\
\hline Madhya Pradesh (rural) & Angina, asthma and diarrhoea & 22 & 677 & $12^{\star}$ & 8 & 36 & 35 \\
\hline \multirow[t]{2}{*}{ Bihar (rural) } & Childhood diarrhoea & NA & 340 & 3 & 0 & 17 & NA \\
\hline & Childhood pneumonia & NA & 340 & 8 & 14 & 60 & NA \\
\hline \multicolumn{8}{|l|}{ China: } \\
\hline Shaanxi Province (rural) & Dysentery and angina & 4 & 82 & 37 & 24 & 52 & NA \\
\hline $\begin{array}{l}\text { Sichuan, Shaanxi, and } \\
\text { Anhui Provinces (rural) }\end{array}$ & Tuberculosis & 4 & 138 & 15 & 25 & 40 & 51 \\
\hline \multicolumn{8}{|l|}{ Kenya: } \\
\hline Nairobi (urban) & $\begin{array}{l}\text { Angina, asthma, diarrhoea, } \\
\text { and tuberculosis }\end{array}$ & 14 & 166 & $32^{*}$ & 22 & 53 & 55 \\
\hline
\end{tabular}

providers with varying qualifications and connections to the formal healthcare sector. The average village in rural Madhya Pradesh-one of the poorest states in India-has 11 healthcare providers within $3 \mathrm{~km}$ of the village, ${ }^{9}$ most of whom have no formal training. ${ }^{10}$ However, informal providers are often not counted when assessing key measures of access such as the ratio of clinicians to patients.

In other countries, non-physician clinicians are an integral and sizeable part of the state machinery but are often excluded when assessing in human resources. ${ }^{1112}$ Studies that count all providers show that access to healthcare is often better than historically imagined in low resource settings. Official statistics that focus only on formal physicians per population miss this important point.

Given that access, more leniently defined, is less of a problem, where do the challenges lie? Primarily, it is the quality of care that patients receive when they access healthcare providers. Table 2 summarises the results of studies that use standardised patients-people recruited from local communities and extensively trained to present the same set of standard symptoms to multiple providers-to assess quality. The standardised patients presented with simple clinical conditions to ensure no disagreement on the correct diagnosis or treatment. This method facilitates a "blind audit" since the same clinical cases can be presented to providers with a wide range of training and qualifications. ${ }^{13} 14$

In India, China, and Kenya most cases were incorrectly diagnosed, and, even using a very lenient definition, simple medical conditions were correctly managed a minority of the time. Although standardised patients in Kenya generally received higher quality care than those in India and China, $90 \%$ of angina presentations in Nairobi were still misdiagnosed as pneumonia. ${ }^{14}$ Across the board, studies find frequent misdiagnosis, overuse of antibiotics and other drugs, and underuse of inexpensive but potentially lifesaving diagnostics and therapies in both public and private sector clinics; all have serious repercussions for health outcomes and expenditure.

Poor quality is not unique to primary care. Another stark example is institutional childbirth. Incentive schemes to encourage women to deliver in public facilities increased the number of institutional deliveries in countries such as Malawi, ${ }^{18}$ India, ${ }^{1920}$ and Rwanda ${ }^{21}$ but did not improve child or maternal outcomes. Why not? It is not for the lack of availability of infrastructure and medicines. According to WHO surveys, lifesaving treatments for women giving birth are widely available and used in most health facilities across countries. However, the availability of these essential treatments is not associated with better maternal outcomes. ${ }^{22}$ Poor implementation, delays in diagnosis and treatment, and silos of care have been hypothesised to at least partly explain excessive mortality and morbidity.

Finally, the hypothesis that poor quality may be due to overwhelmed primary care providers who see too many patients and do not have the time to carefully evaluate or manage them may be incorrect. Clinical observation studies show that most primary care providers see too few patients, rather than too many (fig 1). The average healthcare provider working in a public clinic in rural India, who provides services that are free at the point of use, sees 5.7 patients a day, spending only three minutes with each. In Tanzania, Senegal, and rural Madhya Pradesh (India), doctors in public primary health clinics spend a mere 30 to 40 minutes a day seeing patients.
Qualifications do not equal clinical knowledge Poor quality is often assumed to be due to the large number of informal (ie, untrained) providers. However, even fully trained providers with adequate access to infrastructure often fail to deliver high quality care. This weak link between qualifications and quality reflects two related but conceptually separate issues. Firstly, the quality of medical training varies considerably in many countries. Tests of medical knowledge among physicians and non-physician clinicians in India, ${ }^{25}$ Vietnam, ${ }^{23}$ Nigeria, ${ }^{26}$ Eastern Europe, ${ }^{27}$ and several countries in subSaharan Africa consistently show large variations in within country knowledge, with sizeable numbers of untrained, non-physician clinicians who are more knowledgeable than their fully trained counterparts.

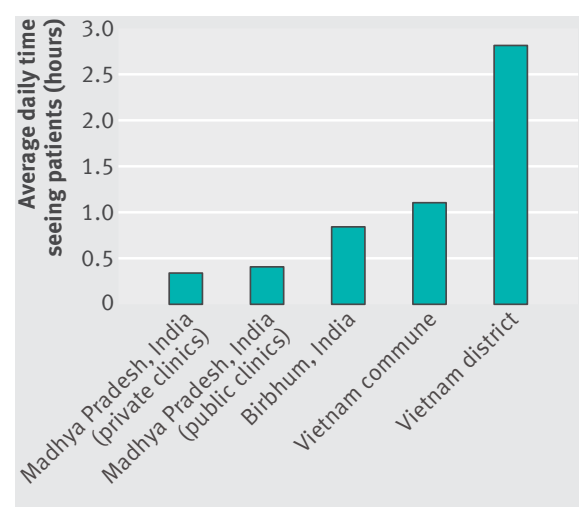

Fig 1 | Total time spent by healthcare providers with patients over a day. The sample from Madhya Pradesh, includes 199 private providers (mostly untrained) and 119 providers in public clinics. The sample from Birbhum, is 256 providers in rural locations, most of whom are not formally trained. The survey from Vietnam is based on a representative sample of 214 commune health facilities (similar to primary health centres) and 171 district hospitals ${ }^{2315} 24$ 


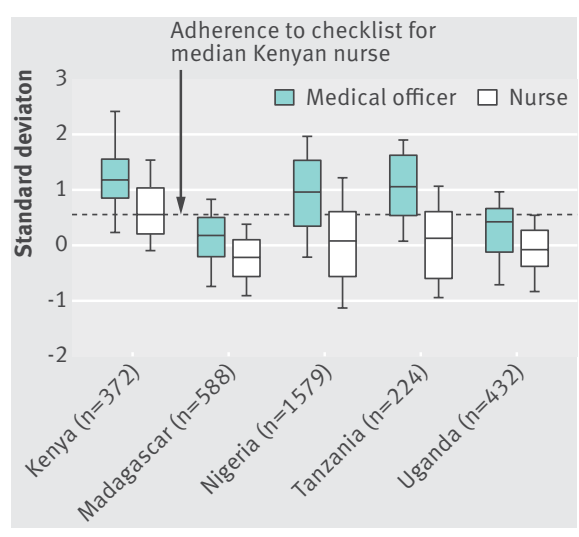

Fig 2 | Variations in medical knowledge of medical officers (fully trained doctors) and nurses assessed by World Bank's Service Delivery Indicators Survey. The boxes show $25^{\text {th }}$ percentile, median, and $75^{\text {th }}$ percentile adherence to condition specific checklist items for the common illnesses, with the whiskers giving the 10th and 9oth percentiles

Figure 2 documents adherence to a medically necessary checklist of questions about medical history and examinations for multiple conditions presented to doctors through medical vignettes in five sub-Saharan African countries. Although fully trained doctors are more likely than nurses to know what questions to ask and examinations to perform, there is considerable overlap between the distributions (fig 2). Within every country, the top $20-50 \%$ of nurses are more knowledgeable than the poorest performing $25 \%$ of doctors. Even between formally trained versus informally trained doctors, doctors with more formal education may only modestly outperform their informally educated peers (fig 3 ).

The translation of qualifications to knowledge varies across countries. The mean Kenyan nurse is more knowledgeable than $21 \%$ of doctors in Kenya, $78 \%$ of doctors in Madagascar, 32\% in Nigeria,

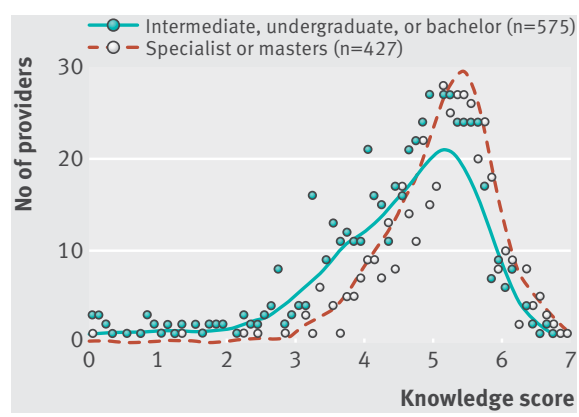

Fig 3 | Relation between medical qualification and knowledge among doctors in Vietnam, as assessed by medical vignettes. The circles show the number of providers in each bin of 0.1 standard deviation across the entire distribution. The corresponding density plots (relative scale) are calculated from the underlying unbinned distributions ${ }^{23}$
$25 \%$ in Tanzania, and 63\% in Uganda (fig 2). There are also wide differences across states in India: informal providers in high performing states like Tamil Nadu are more knowledgeable than fully trained doctors in low performing states like Bihar. The link between qualifications (training) and medical knowledge is surprisingly weak. It is therefore wrong to assume that populations with access to a fully trained doctor in Madagascar enjoy better care than populations with access to a fully trained nurse in Kenya.

Clinical knowledge often fails to translate into clinical practice

Medical knowledge is only loosely tied to actual clinical practice. Providing high quality clinical care requires both knowledge and effort, and when the average clinical interaction lasts 90 seconds, as it does in Delhi's public sector or Vietnam's district hospitals, medical knowledge often does not translate into high quality clinical interactions. ${ }^{28}$ A recent systematic review of consultation time, our best measure of effort, across 68 countries and 28 million consultations found that the average consultation "varied from 48 seconds in Bangladesh to 22.5 minutes in Sweden." In most countries, consultation times averaged less than 10 minutes, and in 15 countries less than 5 minutes. ${ }^{29}$ Short consultation times were more prevalent in low income countries, even in contexts where doctors were seeing just a few patients a day. ${ }^{23}$

Short consultation times imply that even when doctors know what to do, they often fail to do it. There is a persistent, often sizeable, gap between what providers say they will do when faced with a hypothetical patient and what they actually do when they see such a patient (fig 4). Emerging evidence finds large "know-do" gaps in countries as diverse as

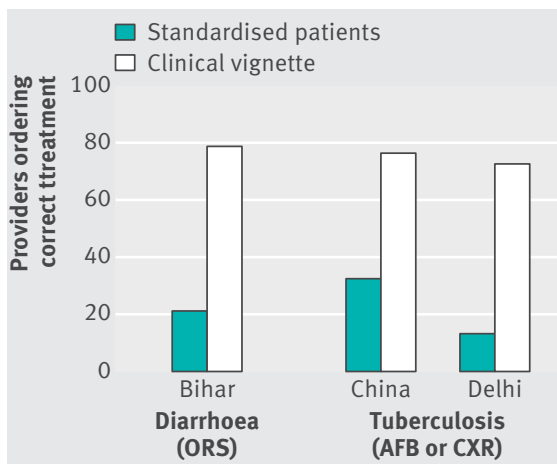

Fig 4 | Differences between how providers said they would manage diarrhoea and turberculosis in clinical vignettes and what they actually did with standardised patients presenting with the symptoms in the vignettes $(O R S=$ oral replacement solution, $A F B=$ acid fast bacilli test, $C X R=$ chest radiography) ${ }^{131730}$
Rwanda, ${ }^{31}$ Tanzania, ${ }^{32}$ India, ${ }^{28}$ China, ${ }^{30}$ and Vietnam. ${ }^{23}$ This know-do gap can be so large that the providers without any formal medical training can provide higher quality care than fully trained doctors. ${ }^{28}$

The idea that the medical profession "has special knowledge ... and will selfregulate" ${ }^{33}$ has already been questioned. ${ }^{34}$ ${ }^{35}$ We are learning that doctors are humans who operate within complex systems. Because they respond to incentives, the same doctors seem to provide more effort (and deliver higher quality care) in private clinics than in public ones, even when structural resources are held equal. In a Beijing hospital, when standardised patients presenting with viral pharyngitis told doctors they would purchase medicines from an external pharmacist (rather than the hospital pharmacy from which the prescriber receives a salary bonus), antibiotic prescriptions fell from $77 \%$ to $11 \% .^{36}$ This 66 percentage point difference suggests doctors knew that prescribing antibiotics was unhelpful but were swayed by financial incentives.

\section{Potential solutions}

We have focused on just one component of quality: effectiveness. Understanding whether similar patterns arise for safety and patient centred care is critical, although there is little reason to believe it would not. The data come from only around a dozen countries, but they include India and China, where a large proportion of the world's poorest people live. Although standardised patients cannot fully capture all clinical scenarios (for practical and ethical reasons), the data that have emerged in recent years suggest the same patterns: big quality problems, a weak link between qualifications and knowledge, and a large gap between knowledge and practice. The evidence suggests that countries need to incorporate quality into their UHC plans at an early stage.

Whether efforts to achieve UHC will translate into better health outcomes depends on how we execute these efforts, and this in turn will determine whether we are able to move from a simple access oriented definition of UHC to truly effective UHC. Emerging data challenge models of care that assume that qualified providers in well resourced clinics guarantee quality. New approaches are needed to ensure that broader investments in healthcare actually lead to better health outcomes, especially for poorer people.

New approaches need to tackle systems that produce medical professionals who are poorly trained, undermotivated, and often assigned to clinics with no peers or mentors and insufficient patient volume to hone skills. These providers consequently leave 
many patients, particularly those with few resources, receiving care that is unhelpful and often harmful.

This will not be an easy process. But clear examples are emerging where these efforts are bearing fruit: mid-level providers who provide high quality care, whether they are anaesthesia assistants in rural Nepalese hospitals or nurses managing HIV care in large parts of Africa. ${ }^{37-39}$ Initiatives to tackle the availability of doctors in rural areas can focus on non-physician providers and training them to be as good, if not better, at providing certain types of care. ${ }^{4041}$

Similarly, countries are realising that placing doctors in rural areas may mean that they see only few patients a day. An alternative is to bring patients from rural areas to urban centres with better facilities, as has been tried with considerable success using ambulance systems in India and medical buses in Brazil. ${ }^{4243}$

Unfortunately, there are other systematic design problems where our knowledge base remains low. For instance, evidence shows that when diagnosis and treatment are "bundled" so that healthcare providers can earn higher incomes by ordering tests or prescribing drugs, their tendency to do so increases. ${ }^{36}$ Breaking the link between diagnoses, drug sales, and laboratory tests can reduce unnecessary tests and drug usage. How to do so in an efficient manner, however, remains an open question.

\section{Conclusion}

Task shifting and new approaches to delivery are just two examples of the kind of innovation needed to achieve effective UHC. Reaching the goals of UHC requires not just more money, but better money. We need additional research and policy work that questions baseline assumptions and normative, or prescriptive, frameworks. We must understand the world as it is, not as we wish it to be. Healthcare providers may make errors, but they often make the same errors again and again, and therefore make "predictable" mistakes; these mistakes are indicative of a broken system. If this predictability is recognised and modelled in policies and strategies to improve global health, we can make important advances. Such recognition has the potential to transform how healthcare is delivered in low income contexts, ultimately improving the lives of billions.

Additional material available on bmj.com: Methods for collecting data on effectiveness of healthcare

Contributors and sources: All authors contributed to the design of the manuscript as well as interpretation of the data. JD provided data for figures used throughout the piece. JD, LW, and RR drafted the manuscript. All authors then reviewed and provided comment. JD, LW and $A$ J received comments and updated the manuscript, after which all authors reviewed and provided feedback and, finally, approval. Mary Dixon Woods also provided substantive feedback throughout the development of the piece. The findings, interpretations, and conclusions expressed here are those of the authors and do not necessarily represent the views of the World Bank, its executive directors, or the governments they represent. Rifat Atun, Niek Klazinga, Fiona Godlee, Ed Kelley, Sheila Leatherman, and Sujatha Rao were part of the working group for the series.

Competing interests: We have read and understood BMJ policy on declaration of interests and have no relevant interests to declare.

Provenance and peer review: Commissioned; externally peer reviewed.

This article is part of a series commissioned by The $B M$ J based on an idea from theHarvard Global Health Institute. The $B M$ J retained full editorial control over external peer review, editing, and publication. Harvard Global Health Institute paid the open access fees.

Jishnu Das, lead economist ${ }^{1}$

Liana Woskie, assistant director ${ }^{2}$

Ruma Rajbhandari, instructor ${ }^{3}$

Kamran Abbasi, executive editor ${ }^{4}$

Ashish Jha, K T Ki, professor of international health ${ }^{5}$

${ }^{1}$ World Bank, Washington, DC, USA

${ }^{2}$ Harvard Initiative on Global Health Quality, Cambridge, MA 02138, USA

${ }^{3}$ Harvard Medical School, Boston, MA, USA

${ }^{4}$ The BMJ, London, UK

${ }^{5}$ Department of Health Policy and Management, Harvard T H Chan School of Public Health, Harvard Global Health Institute, Boston

Correspondence to: AKJha

ajha@hsph.harvard.edu

1 Bendavid E, Holmes CB, Bhattacharya J, Miller G. HIV development assistance and adult mortality in Africa. JAMA 2012;307:2060-7. doi:10.1001/ jama.2012.2001

2 World Health Organization. Eliminating river blindness: highlights from TDR's making a difference. 30 years of research and capacity building in tropical diseases. WHO, 2007.

3 Spector JM, Agrawal P, Kodkany B, et al. Improving quality of care for maternal and newborn health: prospective pilot study of the WHO safe childbirth checklist program. PLoS One 2012;7:e35151. doi:10.1371/journal.pone.0035151

4 Chaudhury N, Hammer JS. Ghost doctors: absenteeism in Bangladeshi health facilities. World Bank, 2004. https://openknowledge.worldbank.org/ handle/10986/17167

5 Chaudhury N, Hammer J, Kremer M, Muralidharan K, Rogers FH. Missing in action: teacher and health worker absence in developing countries. J Econ Perspect 2006;20:91-116. doi:10.1257/089533006776526058

6 Institute of Medicine, Committee on Quality of Health Care in America. Crossing the quality chasm: a new health system for the 21st century. National Academies Press, 2001

7 Scott KW, Jha AK. Putting quality on the global health agenda. N Engl J Med 2014;371:3-5. doi:10.1056/ NEJMp1402157

8 Institute of Medicine, Committee to Design a Strategy for Quality Review and Assurance in Medicare. InLohr KN, ed. Medicare: A strategy for quality assurance. National Academies Press, 1990

9 Das J, Mohpal A. Socioeconomic status and quality of care in rural India: new evidence from provider and household surveys. Health Aff (Millwood) 2016;35:1764-73. doi:10.1377/ hlthaff.2016.0558
10 Banerjee A, Deaton A, Duflo E. Health, health care, and economic development: wealth, health, and health services in rural Rajasthan. Am Econ Rev 2004;94:326-30. doi:10.1257/0002828041301902

11 Sudhinaraset M, Ingram M, Lofthouse HK, Montagu D. What is the role of informal healthcare providers in developing countries? A systematic review. PLoS One 2013;8:e54978. doi:10.1371/journal. pone.0054978

12 Mullan F, Frehywot S. Non-physician clinicians in 47 sub-Saharan African countries. Lancet 2007;370:2158-63. doi:10.1016/S01406736(07)60785-5

13 Das J, Kwan A, Daniels B, et al. Use of standardised patients to assess quality of tuberculosis care: a pilot, cross-sectional study. Lancet Infect Dis 2015;15:1305-13. doi:10.1016/S14733099(15)00077-8

14 Daniels B, Dolinger A, Bedoya G, et al. Use of standardised patients to assess quality of healthcare in Nairobi, Kenya: a pilot, crosssectional study with international comparisons. BMJ Glob Health 2017;2:e000333. doi:10.1136/ bmigh-2017-000333

15 Das J, Holla A, Das V, Mohanan M, Tabak D, Chan B. In urban and rural India, a standardized patient study showed low levels of provider training and huge quality gaps. Health Aff (Millwood) 2012;31: 2774-84 doi:10.1377/hlthaff.2011.1356

16 Sylvia S, Shi Y, Xue H, et al. Survey using incognito standardized patients shows poor quality care in China's rural clinics. Health Policy Plan 2015;30: 322-33. doi:10.1093/heapol/czu014

17 Mohanan M, Vera-Hernández M, Das V, et al. The know-do gap in quality of health care for childhood diarrhea and pneumonia in rural India. JAMA Pediatr 2015;169:349-57. doi:10.1001/ jamapediatrics.2014.3445

18 Godlonton S, Okeke EN. Does a ban on informal health providers save lives? Evidence from Malawi. J Dev Econ 2016;118:112-32. doi:10.1016/j. jdeveco.2015.09.001

19 Powell-Jackson T, Mazumdar S, Mills A. Financial incentives in health: New evidence from India's Janani Suraksha Yojana. J Health Econ 2015;43: 154-69 doi:10.1016/j.jhealeco.2015.07.001

20 Mohanan M, Bauhoff S, La Forgia G, Babiarz KS, Singh K, Miller G. Effect of Chiranjeevi Yojana on institutional deliveries and neonatal and maternal outcomes in Gujarat, India: a difference-in-differences analysis. Bull World Health Organ 2014;92:187-94. doi:10.2471/BLT.13.124644

21 Chari A, Okeke E. Can institutional deliveries reduce newborn mortality? Evidence from Rwanda. RAND, 2014.

22 Souza JP, Gülmezoglu AM, Vogel I, et al. Moving beyond essential interventions for reduction of maternal mortality (the WHO Multicountry Survey on Maternal and Newborn Health): a cross-sectional study. Lancet 2013;381:1747-55. doi:10.1016/ S0140-6736(13)60686-8

23 World Bank. Quality and equity in basic health care services in Vietnam: findings from the 2015 Vietnam district and commune health facility survey. World Bank, 2016.

24 Das J, Chowdhury A, Hussam R, Banerjee AV. The impact of training informal health care providers in India: A randomized controlled trial. Science 2016;354:aaf7384. doi:10.1126/science. aaf7384

25 Das J, Hammer J. Which doctor? Combining vignettes and item response to measure clinical competence. J Dev Econ 2005;78:348-83. doi:10.1016/j. jdeveco.2004.11.004

26 Wane W, Martin GH. Education and health services in Uganda: data for results and accountability. World Bank, 2013.

27 Peabody JW, DeMaria L, Nguyen SN, Smith O, Hoth A. Quality of care in six eastern European countries using clinical performance and value vignettes: a cross-sectional study. Bull World Health Organ 2017. 
28 Das J, Hammer J. Money for nothing: the dire straits of medical practice in Delhi. World Bank, 200510.1596/1813-9450-3669.

29 Irving G, Neves AL, Dambha-Miller H, et al. International variations in primary care physician consultation time: a systematic review of 67 countries. BMJ Open 2017;7:e017902. doi:10.1136/bmjopen-2017-017902

30 Sylvia S, Xue H, Zhou C, et al. Tuberculosis detection and the challenges of integrated care in rural China: A cross-sectional standardized patient study. PLoS Med 2017:14:e1002405. doi:10.1371/journal. pmed.1002405

31 Gertler P, Vermeersch C. Using performance incentives to improve health outcomes. World Bank, 201210.1596/1813-9450-6100.

32 Leonard KL, Masatu MC. The use of direct clinician observation and vignettes for health services quality evaluation in developing countries. Soc Sci Med 2005;61:1944-51. doi:10.1016/j. socscimed.2005.03.043

33 Berwick D. The 9 changes needed to make health care more moral. 2016. https://www.advisory.com/ daily-briefing/2016/04/12/berwick.

34 Brennan TA, Leape LL, Laird NM, et al. Incidence of adverse events and negligence in hospitalized patients. Results of the Harvard Medical Practice Study I. N Engl J Med 1991;324:370-6. doi:10.1056/NEJM199102073240604

35 Landrigan CP, Parry GJ, Bones CB, Hackbarth AD, Goldmann DA, Sharek PJ. Temporal trends in rates of patient harm resulting from medical care. $N$ Engl J Med 2010;363:2124-34. doi:10.1056/ NEJMsa1004404

36 Currie J, Lin W, Meng J. Addressing antibiotic abuse in China: an experimental audit study. J Dev Econ 2014;110:39-51. doi:10.1016/j. jdeveco.2014.05.006

37 Shumbusho F, van Griensven J, Lowrance D, et al. Task shifting for scale-up of HIV care: evaluation of nurse-centered antiretroviral treatment at rural health centers in Rwanda. PLoS Med 2009;6:e1000163. doi:10.1371/journal.pmed.1000163

38 Cohen R, Lynch S, Bygrave H, et al. Antiretroviral treatment outcomes from a nurse-driven. community-supported HIV/AIDS treatment programme in rural Lesotho: observational cohort assessment at two years. J Int AIDS Soc 2009;12:23. doi:10.1186/1758-2652-12-23

39 Mavalankar D, Sriram V. Provision of anaesthesia services for emergency obstetric care through task shifting in South Asia. Reprod Health
Matters 2009;17:21-31. doi:10.1016/S09688080(09)33433-3

40 Sanne I, Orrell C, Fox MP, et al, CIPRA-SA Study Team. Nurse versus doctor management of HIVinfected patients receiving antiretroviral therapy (CIPRA-SA): a randomised non-inferiority trial. Lancet 2010;376:33-40. doi:10.1016/S01406736(10)60894-X

41 Fairall L, Bachmann MO, Lombard C, et al. Task shifting of antiretroviral treatment from doctors to primary-care nurses in South Africa (STRETCH) a pragmatic, parallel, cluster-randomised trial. Lancet 2012;380:889-98. doi:10.1016/S0140 6736(12)60730-2

42 Babiarz KS, Mahadevan SV, Divi N, Miller G. Ambulance service associated with reduced probabilities of neonatal and infant mortality in two Indian states. Health Aff (Millwood) 2016;35: 1774-82. doi:10.1377/hlthaff.2016.0564

43 Marques AldS. Lima MdS. O sistema estadual de transporte em saúde de Minas Gerais: relato de experiência. Revista de Administração Hospitalar e Inovação em Saúde 2012;8:81-4.

Cite this as: $B M J$ 2018;361:k1716 http://dx.doi.org/10.1136/bmj.k1716

This is an Open Access article distributed in accordance with the Creative Commons Attribution Non Commercial (CC BY-NC 4.0) license, which permits others to distribute, remix, adapt, build upon this work non-commercially, and license their derivative works on different terms, provided the original work is properly cited and the use is non-commercial. See: http://creativecommons.org/licenses/by-nc/4.0/. 